\title{
The search for a long-lasting circumferential tracheal conduit: Belsey's problem and ours
}

\author{
Raja M. Flores, MD
}

\author{
From the Department of Thoracic Surgery, Icahn School of Medicine, Mount Sinai Health System, New York, NY. \\ Disclosure: Author has nothing to disclose with regard to commercial support. \\ Received for publication Aug 15, 2016; accepted for publication Aug 15, 2016. \\ Address for reprints: Raja M. Flores, MD, Department of Thoracic Surgery, Mount Sinai Health System, Icahn \\ School of Medicine at Mount Sinai, One Gustave L. Levy Place, Box 1023, New York, NY 10029 (E-mail: \\ raja.flores@mountsinai.org). \\ J Thorac Cardiovasc Surg 2016;152:1233-4 \\ $0022-5223 / \$ 36.00$ \\ Copyright (C) 2016 by The American Association for Thoracic Surgery \\ http://dx.doi.org/10.1016/j.jtcvs.2016.08.026
}

In 1950, Ronald Belsey ${ }^{1}$ described several clinical scenarios of large tracheal defects not amenable to resection and reconstruction that were repaired with wire and thigh fascia lata with the residual connecting sliver of trachea as a scaffold (Figure 1). The outcome was poor. Belsey ${ }^{1}$ stated "The intrathoracic portion of the trachea is the last unpaired organ in the body to fall to the surgeon, and the successful solution of the problem of its reconstruction may mark the end of the expansionist epoch in the development of surgery." Unfortunately, during the intervening 65 years, little progress has been made in crafting a circumferential tracheal conduit with acceptable long-term results.

Today, large tracheal defects are uncommon. They typically are the result of malignancy, radiation, or congenital abnormalities. Lesions greater than half the tracheal length are usually not amenable to resection and reconstruction. Such defects are usually managed by T-tubes, necessitating lifelong and frequent surgical interventions to maintain luminal patency. Quality of life is compromised, and enteral tube feedings are often required.

Although prosthetics are used routinely in the vascular system in the form of blood conduits and heart valves, their interface with the bacteria-colonized world of the airway results in infection and failure. Artificial gastrointestinal and genitourinary system conduits have met with the same unsuccessful, infectious fate. An artificial trachea requires unique physiologic and anatomic properties to avoid infection. Cough and mucociliary action allows for the expulsion of mucous, granulation tissue, and other debris. The ideal airway conduit cannot simply be an inanimate tube.

Research has been performed in dogs, sheep, and pigs; unfortunately, however, the minimal progress that has been achieved has not translated to humans. The reasons for these failures are multifactorial, but it is clear that there are no conduits that are ready for prime time yet. Several studies have looked at bioengineering with stem cells, aortic homografts, tracheal transplants, 3-dimensional printing,

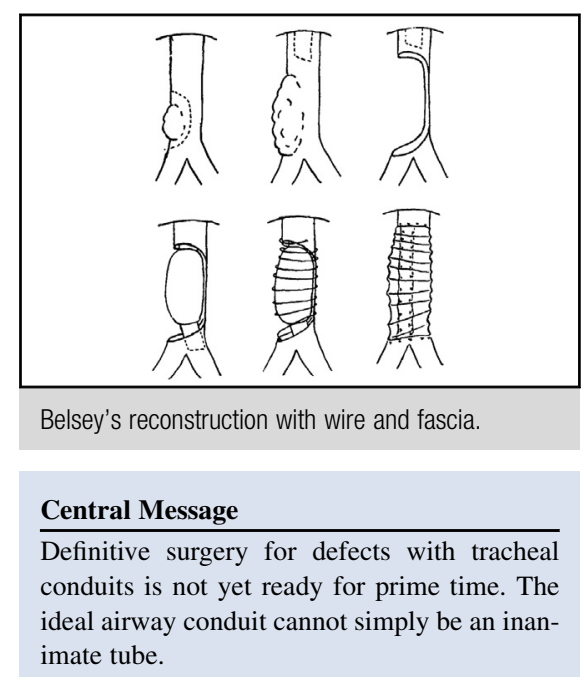

See Article page 1388 .

acellular dermal matrix, and stents in humans, with little success. Airway compromise usually occurs within a month's time. The greatest hindrances to progress are infection, granulation tissue, contraction, and the accumulation of intraluminal debris. When modest short-term success is achieved, stricture or malacia usually sets in.

In humans, vascularized fasciocutaneous, myocutaneous, and omental flaps have been used with modest success. ${ }^{2}$ In their article in this issue of the Journal, Udelsman and colleagues $^{3}$ demonstrate modest success with bioprosthetic materials as well. Progress has been slow, and animal research has been wastefully repetitive without novel advancement. We must build on what these human studies have taught us and not continue unsuccessfully to reinvent the same malfunctioning wheel.

So when patients with such lesions cross our path, how do we help them? First we must remember that definitive surgical intervention is not necessary for the patient's survival. T-tubes work just fine. Our goal is to improve the quality of life. Unless we can provide a reliable, long-lasting solution, an unpredictable life-threatening experimental surgical intervention is not justified to treat a stable, functional patient.

Although the pioneering group from Massachusetts General Hospital ${ }^{3}$ has demonstrated some progress in their study with regard to tracheal replacement, we must heed the words of their teacher Hermes Grillo, "Success has been announced episodically over the decades in each of these 

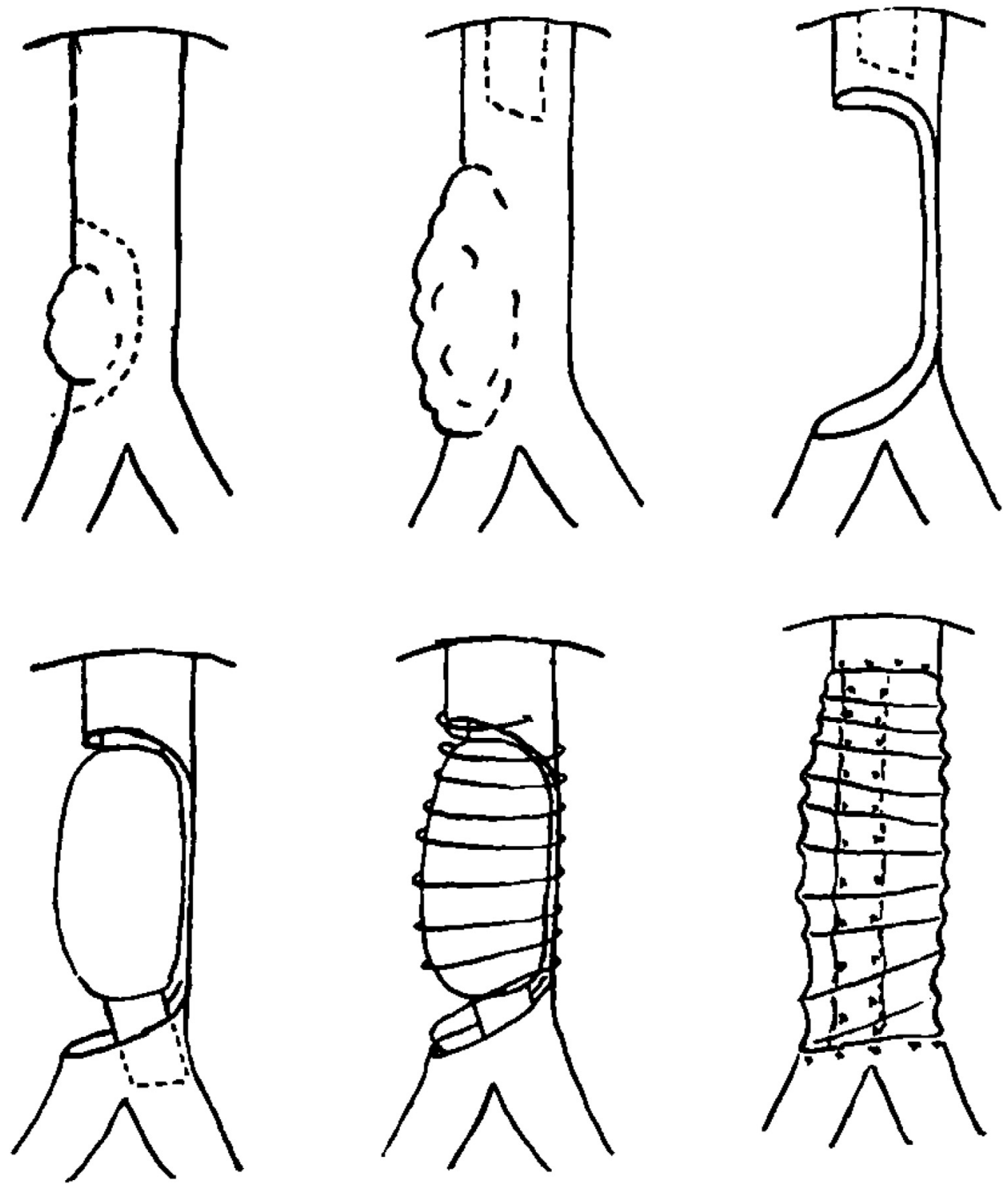

FIGURE 1. The first diagram shows the extent of resection at the first operation. The remainder show the extent of the recurrence 1 year later, the extent of the resection, and the method of reconstruction with wire and fascia. Reprinted with the permission of John Wiley and Sons from Belsey R. Resection and reconstruction of the intrathoracic trachea. Br J Surg. 1950;38:200-5.

categories, but thus far no one replacement method has held for the long term in any safe and practicable manner." ${ }^{4}$ This still holds true today.

\section{References}

1. Belsey R. Resection and reconstruction of the intrathoracic trachea. Br J Surg. 1950;38:200-5.
2. Fabre D, Kolb F, Fadel E, Mercier O, Mussot S, Le Chevalier T, et al. Successful tracheal replacement in humans using autologous tissues: an 8-year experience. Ann Thorac Surg. 2013;96:1146-55.

3. Udelsman BV, Eaton J, Muniappan A, Morse CR, Wright CD, Mathisen DJ. Repair of large airway defects with bioprosthetic materials. J Thorac Cardiovasc Surg. 2016:152:1388-97.

4. Grillo HC. Tracheal replacement. In: Grillo HC, ed. Surgery of the trachea and bronchi. Hamilton, Ontario, Canada: BC Decker; 2004:840. 